\title{
Variation in Planned Resection of CAM FAI Based on Surgeon Experience
}

\author{
Derek Ochiai, ${ }^{1}$ Skye Donovan, ${ }^{1,2}$ Farshad Adib, ${ }^{3}$ and Eric Guidi ${ }^{2}$ \\ ${ }^{1}$ Nirschl Orthopedic Center, Arlington, VA 22205, USA \\ ${ }^{2}$ Marymount University, Arlington, VA 22207, USA \\ ${ }^{3}$ University of Maryland, Baltimore, MD 21201, USA
}

Correspondence should be addressed to Skye Donovan; jdonovan@marymount.edu

Received 31 July 2015; Revised 25 October 2015; Accepted 9 November 2015

Academic Editor: Padhraig O'Loughlin

Copyright (C) 2015 Derek Ochiai et al. This is an open access article distributed under the Creative Commons Attribution License, which permits unrestricted use, distribution, and reproduction in any medium, provided the original work is properly cited.

\begin{abstract}
Introduction. Currently, there are no definitive guidelines for the resection of a cam lesion. The purpose of this study was to investigate factors indicating the potential differences in low and high volume hip arthroscopists in marking the area of resection in cam lesions using X-rays for preoperative planning. Methods. Thirty-nine surgeons with varying levels of hip arthroscopy experience participated in the study. Surgeons filled out a survey and traced the area of optimal resection on radiographs with varying amounts of cam FAI. Participants were grouped by number of hip arthroscopies performed, years of surgical experience, and number of surgeries performed. Results. Surgeons who perform osteoplasty as a high percentage of their total hip surgeries per year correlate to the total number of hip arthroscopies performed per year $(r=0.412, p<0.05)$ and number of years of experience $(r=0.72$, $p<0.01)$. Surgeons performing greater than 50 cases per year traced a larger resection area for 3 different patients' radiographs as compared to those performing less than 50 cases per year $(117 \%, 143 \%$, and $173 \%, p<0.05)$. Conclusions. This study demonstrates that surgeons with less experience (decreased number of years operating and total number of surgeries) plan for resecting less cam than do experienced surgeons.
\end{abstract}

\section{Introduction}

The understanding of femoroacetabular impingement (FAI) continues to evolve. Preoperative X-ray and three-dimensional computed tomography scans are helpful to evaluate the extent of cam lesions [1]. Cam FAI is a structural, mechanical problem, necessitating symptomatic patients to have surgery. Surgery can be performed arthroscopically or by an open technique. Arthroscopic surgery has the advantages of most minimally invasive surgeries previously described in the literature. The advantages of open treatment include easy access to all hip structures and facilitation of intraoperative ranging of the hip at extremes of motions. In open surgery, the recovery time is longer secondary to the highly invasive nature of the operation and increased potential risk for avascular necrosis [2].

The use of hip arthroscopy for definitive treatment of FAI is increasing [3]. Arthroscopic management of FAI is improving, with excellent outcomes reported in the literature at early-term follow-up [4-7]. Despite the increase in FAI arthroscopy, the learning curve in planned resection of cam FAI has not been determined based on consistency and appropriate resection.

Despite availability of the advanced imaging techniques, the X-ray is still the cornerstone of preoperative planning for FAI surgery. Incompletely treated FAI is the number one cause of revision hip arthroscopy [8]. Appropriate cam resection is imperative to the success of the surgery. Martin et al. reported underresections of cam FAI, due to the learning curve for hip arthroscopies [9]. Learning curves for surgeons have been assessed in order to determine skill level and to improve existing education techniques. Shoulder and knee arthroscopy studies demonstrate that the number of surgeries and years of experience correlate with better surgical outcomes and decrease in operative time [10-16].

Currently, there is no description of the learning curve for preoperative planning for FAI osteoplasty using X-ray. By 
surveying surgeons with differing levels of hip arthroscopy experience and measuring preferred cam resection area on digital images, this study investigates factors that are associated with differences amongst surgeons in marked area of resection. Specifically the research question of interest is, do surgeons with more experience resect more in preoperative planning for FAI than those who are novice? Our goal is to identify survey characteristics that would eliminate variability in amount of resection preoperatively for cam FAI osteoplasty. This study intends to demonstrate a learning curve for surgeons (timeframe/performance standards) and to assess whether their preoperative planning would be similar to those who are experienced FAI surgeons.

\section{Methods and Materials}

Upon approval by the Marymount University Institutional Review Board, a total of 39 clinicians participated in the study. All of the participants were Board Certified orthopedic surgeons registered for the AANA Master's Experience in Hip Arthroscopy Course (Rosemont, IL). All of the subjects completed a survey describing their surgical history and level of experience (see the appendix).

In addition, the subjects were asked to evaluate the same digital radiographs of three patients with varying amounts of cam FAI. All 3 of the patients were seen at one center and were examined by the same highly experienced hip arthroscopist, with radiographs taken by one technician. High quality digital reproductions of A-P and Dunn lateral view radiographs were provided to the surgeons (Figure 1). Oral instructions were provided to all of the clinicians at the same time; they were asked to trace the area of optimal resection of the cam lesions in all images which were printed and distributed to them; investigators left the room during the tracing. These images were then scanned, converted to JPEG images, and digitally analyzed. The tracings (Figure 2) made by the study participants were retraced using image analysis software (Fiji/ImageJ software available at http://www.nih.gov/). This software also calculated area of resection for each image in pixels, which were compared between participants. Spatial calibration was accomplished by dividing pixels $/ \mathrm{mm}$ and set for future images through Fiji/ImageJ software.

A single author performed all of the analyses to limit interrater error, who was blinded to all patient data. Results from the survey were used to describe surgeon characteristics and used in secondary analysis to determine correlations between survey responses and area indicated in the radiographs. Analysis of variance (ANOVA) was used as the primary analysis for subgroup characteristics. When significant differences were found, comparisons were made using a Bonferroni post hoc analysis. This analysis revealed differences only upon reaching 50 surgeries per year, allowing us to analyze the data by dividing surgeons into 2 groups, less than 50 surgeries and greater than 50, with no differences in greater than 50 or greater than 100 surgeries performed per year. For secondary data analysis, subjects were grouped according to the number of surgeries they performed. Secondary analysis employed the use of Student's $t$-tests and Pearson's correlations to assess differences in area of resection
TABLE 1: Surgeon characteristics as identified by survey.

\begin{tabular}{lccc}
\hline Descriptor & Min & Max & Mode \\
\hline Years performing surgery & 1 & 25 & 1 \\
Number of surgeries performed & 0 & $>100$ & $<5$ \\
\% of surgeries including osteoplasty & $<25 \%$ & $>75 \%$ & $>75 \%$ \\
\hline
\end{tabular}

and the relationship between survey responses and calculated areas. A level of significance was set at $p<0.05$. SPSS (version 17.0 Chicago, IL) was used for all statistical analyses.

\section{Results}

Study participants were grouped into instructors versus attendees. Of the 39 interviewees, 14 were instructors and 25 were attendees. Twenty-six of the participants had been performing surgeries for less than 5 years. The number of surgeries performed varied widely, with 26 surgeons performing $<20$ surgeries, 2 performing between 31 and 50, and 11 performing over 50 . Minimum and maximum values and most frequently noted responses are outlined in Table 1 to illustrate the variance between participants.

Additional survey review revealed that instructors of the hip arthroscopy course were more likely to perform a cam osteoplasty compared to attendees $(r=0.69, p<0.01)$. Among the attendees, the number of surgeries per year $(r=0.72, p<0.01)$ shows a strong correlation with those who perform osteoplasty, while the number of years of experience $(r=0.412, p<0.05)$ has a significant but moderate correlation. From survey data analysis, participants were grouped according to number of hip arthroscopies performed after finding a cut-off difference at 50 surgeries per year, as determined through post hoc analysis of our ANOVA (Table 1.) A positive correlation was found between number of years of surgical experience and number of surgeries performed per year $(r=0.56, p<0.01)$. Pearson's test revealed a moderate but significant correlation of number of surgeries performed and area of resection for the 3 radiographs $(r=0.39,0.47$, and $0.39, p<0.05)$.

Student's $t$-test detected significant differences in area of resection between groups. It is important to note that the radiographs all depicted obvious cam lesions. Surgeons performing greater than 50 cases per year traced a larger area of resection for the 3 patients' radiographs as compared to those performing less than 50 cases per year $(117 \%, 143 \%$, and $173 \%, p<0.05)$ as illustrated in Table 2 . No differences were seen between surgeons who performed $>50$ versus $>$ 100 surgeries per year.

\section{Discussion}

Because of the steep learning curve in the arthroscopic cam FAI osteoplasty and regional access to bony pathology arthroscopically, there is always a concern about the adequacy of resection of cam lesion [17-19]. Potential problems include inaccurate resection, underresection, and overresection, which may lead to suboptimal outcomes such as residual impingement or the creation of structural instability. One tool 
TABLE 2: Average areas of resection for cam lesions.

\begin{tabular}{lccc}
\hline Number of surgeries performed per year & Image 1 area (pixels) & Image 2 area (pixels) & Image 3 area (pixels) \\
\hline Less than 50 & $10243.7 \pm 1545.5^{*}$ & $17281.8 \pm 6359.8^{*}$ & $6669.5 \pm 4075.8^{*}$ \\
More than 50 & $12413 \pm 2796.8$ & $23765.9 \pm 8542.3$ & $10184.8 \pm 7208.4$ \\
\hline
\end{tabular}

Statistically significant differences denoted by ${ }^{*}(p<0.05)$ as compared to $>50$ surgeries performed per year.

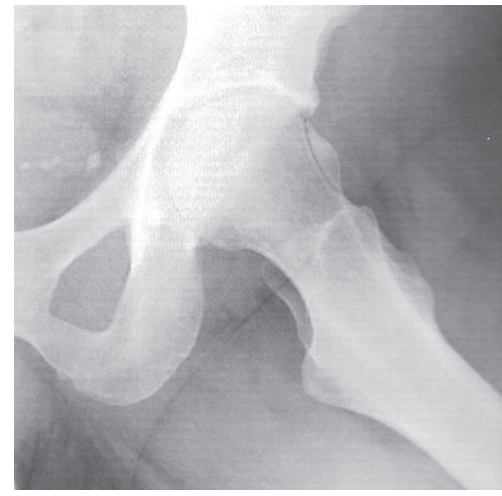

Image 1

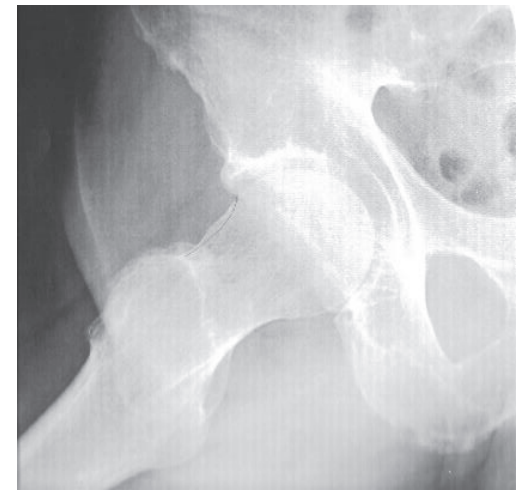

Image 2

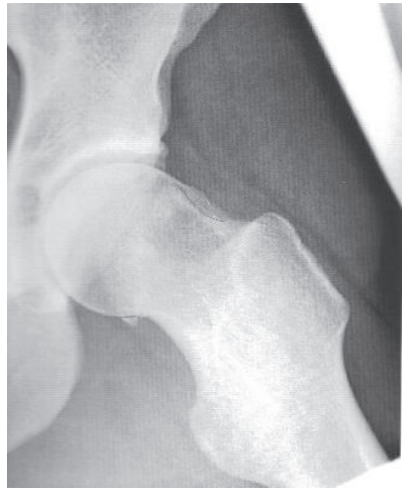

Image 3

FIGURE 1: Cam images presented to study participants.

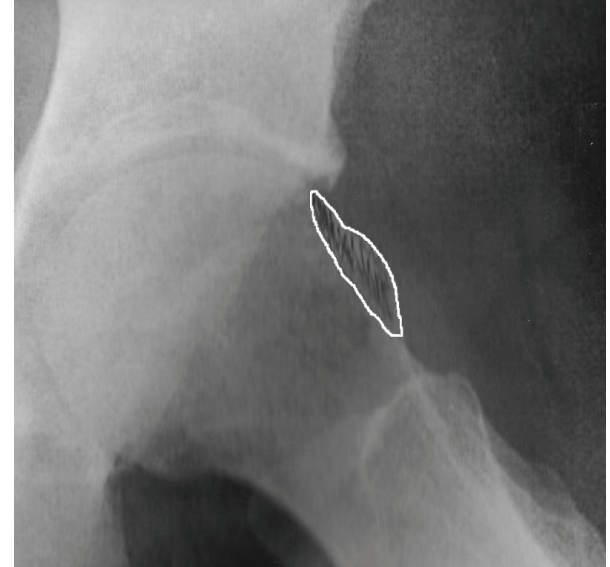

FIGURE 2: Scanned image of physician traced FAI lesion, with subsequent area determination using Fiji/ImageJ software.

to prevent these problems is preoperative planning. In our study, we provide an inexpensive tool [digitized radiographs and free software] to evaluate this skill level noninvasively. Our study supports that preoperative planning on X-ray is significantly different for those surgeons with greater than 50 surgeries per year compared to those with less than 50 per year $(p<0.01)$. There were significant differences in the area of resection between the 2 groups of surgeons, with those performing greater than 50 surgeries per year planning to resect more than the relatively inexperienced surgeons. Underresection by less experienced surgeons runs the risk of needing revision surgery or continued impingement. No difference was seen between surgeons who performed $>50$ versus $>100$ surgeries per year. Surgeons performing more than 50 hip arthroscopies per year planned surgical resection with similar variability as surgeons performing more than 100 , and the variability was less than the surgeons performing $<50$ hip arthroscopies.

This study does not define the "correct" area of resection; it focuses on changes in variability of planned osteoplasty to experience. Likewise, the study did not focus on appropriateness of resection, the images used all had a moderate to severe cam lesion, and the participants were all in a course for arthroscopic management of this condition; thus each participant had a potential bias as to whether resection was necessary. Although this study identifies differences in planned resection, it does not speak to the capability of these surgeons' ability to accomplish a successful outcome.

\section{Limitations}

One of our limitations is the narrow population studied. Since our study group contained all course attendees, they all have vested interest in hip arthroscopy. Additionally, there were only 3 cases for each surgeon to examine; increasing this number may have shown more differences. Also, as a survey study, we chose to not use open-ended questions, but we rather assigned arbitrary cut-offs for the categories of number of surgeries per year. In doing so we felt we were eliminating recall bias: however, this study may slightly over- or underestimate the true number of surgeries related to the learning curve. For our analysis, we used post hoc results and identified 50 surgeries per year as a cut-off value; basing our results on this measurement has the potential to introduce error. We used a blinded review; however, we only used one reviewer, which could introduce bias to our study. Additionally, this study does not measure the actual surgical performance, which could potentially differ from a 
planned surgical resection. Lastly, this study is solely based on radiographs and did not explore other methods of evaluation which play a role in preoperative planning.

\section{Conclusions}

The primary objective of this study was to determine if surgeons of varying experience levels exhibited differences in preoperative planning methods for resection of FAI using hip arthroscopy. Our team evaluated characteristics between participants and grouped them by volume of surgeries to determine correlations to preferred area of surgical resection. This study demonstrates a positive correlation between number of surgeries performed and the area of planned resection. Those surgeons with less experience plan for less cam resection than those with more experience. In addition we introduced a method of evaluating and quantifying amount of resection for preoperative planning. This study can act as a foundation for future studies wishing to determine surgical skills and may help provide teaching tools or benchmarks that could be achieved during the learning curve and to facilitate studies based on surgical experience, surgical outcomes, and amount of resection. Our preoperative planning method might be a helpful tool to determine the amount of cam osteoplasty.

\section{Appendix}

\section{Complete Hip Arthroscopy Survey: Hip FAI Surgeon Questionnaire}

Please Answer All Questions. Indicate answer choice by checking the appropriate box or responding on line provided

(1) In what capacity are you attending this course?

\section{$\square$ Instructor \\ $\square$ Attendee}

(2) How many years have you performed hip arthroscopy as an attending?

$$
\begin{aligned}
& \square 0-12 \text { mos } \\
& \square \text { if }>12 \text { mos, please provide \# of years - }
\end{aligned}
$$

(3) Approximately how many hip arthroscopies do you perform per year?

$$
\begin{aligned}
& \square \text { Less than five } \\
& \square 5-10 \\
& \square 11-20 \\
& \square 21-30 \\
& \square 31-50 \\
& \square 51-100 \\
& \square \text { Greater than } 100
\end{aligned}
$$

(4) Please estimate the percentage of hip arthroscopies that you perform that involve osteochondroplasty?

$\square$ Less than $25 \%$

$\square 26-50 \%$

\section{$51-75 \%$ \\ $\square$ Greater than $75 \%$}

(5) Please estimate, in your opinion, what the overall average of all hip arthroscopies performed in the United States involve osteochondroplasty?

$$
\begin{aligned}
& \square \text { Less than } 25 \% \\
& \square 26-50 \% \\
& \square 51-75 \% \\
& \square \text { Greater than } 75 \%
\end{aligned}
$$

(6) In your opinion, what is the most common reason that you would NOT address existing femoroacetabular impingement while performing a hip arthroscopy?

$$
\begin{aligned}
& \square \text { Patient age } \\
& \square \text { Patient has osteoporosis } \\
& \square \text { Osteochondroplasty is not necessary } \\
& \square \text { Osteochondroplasty is not covered by insur- } \\
& \text { ance } \\
& \square \text { Technically demanding procedure } \\
& \square \text { I would always address FAI with an osteo- } \\
& \text { plasty }
\end{aligned}
$$

\section{Conflict of Interests}

The authors declare that there is no conflict of interests regarding the publication of this paper.

\section{Acknowledgments}

Financial affiliations include Tenex Health, Smith \& Nephew, Arthrex, and Breg. The authors would like to thank Dr. Megan Geiger for her preparation of the abstract and poster associated with this study.

\section{References}

[1] S. Nordeck, J. Flanagan, L. Tenorio, W. Robertson, and A. Chhabra, "3-D Isotropic MR imaging for planning bone reconstruction in patients with femoroacetabular impingement," Radiologic Technology, vol. 87, no. 1, pp. 21-28, 2015.

[2] A. H. Gomoll, G. Pappas, B. Forsythe, and J. J. P. Warner, "Individual skill progression on a virtual reality simulator for shoulder arthroscopy: a 3-year follow-up study," American Journal of Sports Medicine, vol. 36, no. 6, pp. 1139-1142, 2008.

[3] S. Murphy, M. Tannast, Y.-J. Kim, R. Buly, and M. B. Millis, "Debridement of the adult hip for femoroacetabular impingement: indications and preliminary clinical results," Clinical Orthopaedics and Related Research, no. 429, pp. 178-181, 2004.

[4] D. Guttmann, R. D. Graham, M. J. MacLennan, and J. H. Lubowitz, "Arthroscopic rotator cuff repair: the learning curve," Arthroscopy, vol. 21, no. 4, pp. 394-400, 2005.

[5] N. R. Howells, M. D. Brinsden, R. S. Gill, A. J. Carr, and J. L. Rees, "Motion analysis: a validated method for showing skill levels in arthroscopy," Arthroscopy, vol. 24, no. 3, pp. 335-342, 2008. 
[6] A. Insel, B. Carofino, R. Leger, R. Arciero, and A. D. Mazzocca, "The development of an objective model to assess arthroscopic performance," The Journal of Bone \& Joint Surgery-American Volume, vol. 91, no. 9, pp. 2287-2295, 2009.

[7] P. J. O’Neill, A. J. Cosgarea, J. A. Freedman, W. S. Queale, and E. G. McFarland, "Arthroscopic proficiency: a survey of orthopaedic sports medicine fellowship directors and orthopaedic surgery department chairs," Arthroscopy, vol. 18, no. 7, pp. 795-800, 2002.

[8] R. Ganz, J. Parvizi, M. Beck, M. Leunig, H. Nötzli, and K. A. Siebenrock, "Femoroacetabular impingement: a cause for osteoarthritis of the hip," Clinical Orthopaedics and Related Research, no. 417, pp. 112-120, 2003.

[9] H. D. Martin, B. T. Kelly, M. Leunig et al., "The pattern and technique in the clinical evaluation of the adult hip: the common physical examination tests of hip specialists," Arthroscopy, vol. 26, no. 2, pp. 161-172, 2010.

[10] C. M. Larson, C. A. Guanche, B. T. Kelly, J. C. Clohisy, and A. S. Ranawat, "Advanced techniques in hip arthroscopy," Instructional Course Lectures, vol. 58, pp. 423-436, 2009.

[11] C. M. Larson and M. R. Giveans, "Arthroscopic debridement versus refixation of the acetabular labrum associated with femoroacetabular impingement," Arthroscopy, vol. 25, no. 4, pp. 369-376, 2009.

[12] M. J. Philippon, K. K. Briggs, Y.-M. Yen, and D. A. Kuppersmith, "Outcomes following hip arthroscopy for femoroacetabular impingement with associated chondrolabral dysfunction: minimum two-year follow-up," The Journal of Bone \& Joint SurgeryBritish Volume, vol. 91, no. 1, pp. 16-23, 2009.

[13] L. Bogunovic, M. Gottlieb, G. Pashos, G. Baca, and J. C. Clohisy, "Why do hip arthroscopy procedures fail?" Clinical Orthopaedics and Related Research, vol. 471, no. 8, pp. 25232529, 2013.

[14] W. C. Brunner, J. R. Korndorffer Jr., R. Sierra et al., "Determining standards for laparoscopic proficiency using virtual reality," American Surgeon, vol. 71, no. 1, pp. 29-35, 2005.

[15] A. Brunner, M. Horisberger, and R. F. Herzog, "Evaluation of a computed tomography-based navigation system prototype for hip arthroscopy in the treatment of femoroacetabular cam impingement," Arthroscopy, vol. 25, no. 4, pp. 382-391, 2009.

[16] A. H. Gomoll, R. V. O’Toole, J. Czarnecki, and J. J. P. Warner, "Surgical experience correlates with performance on a virtual reality simulator for shoulder arthroscopy," The American Journal of Sports Medicine, vol. 35, no. 6, pp. 883-888, 2007.

[17] J. W. T. Byrd and K. S. Jones, "Arthroscopic Femoroplasty in the management of cam-type femoroacetabular impingement," Clinical Orthopaedics and Related Research, vol. 467, no. 3, pp. 739-746, 2009.

[18] A. Kassarjian, L. S. Yoon, E. Belzile, S. A. Connolly, M. B. Millis, and W. E. Palmer, "Triad of MR arthrographic findings in patients with cam-type femoroacetabular impingement," Radiology, vol. 236, no. 2, pp. 588-592, 2005.

[19] C. W. A. Pfirrmann, S. R. Duc, M. Zanetti, C. Dora, and J. Hodler, "MR arthrography of acetabular cartilage delamination in femoroacetabular cam impingement," Radiology, vol. 249, no. 1, pp. 236-241, 2008. 


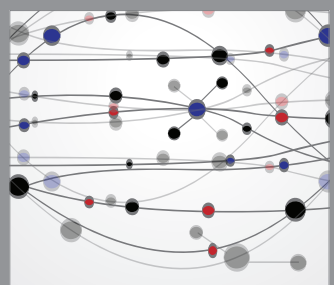

The Scientific World Journal
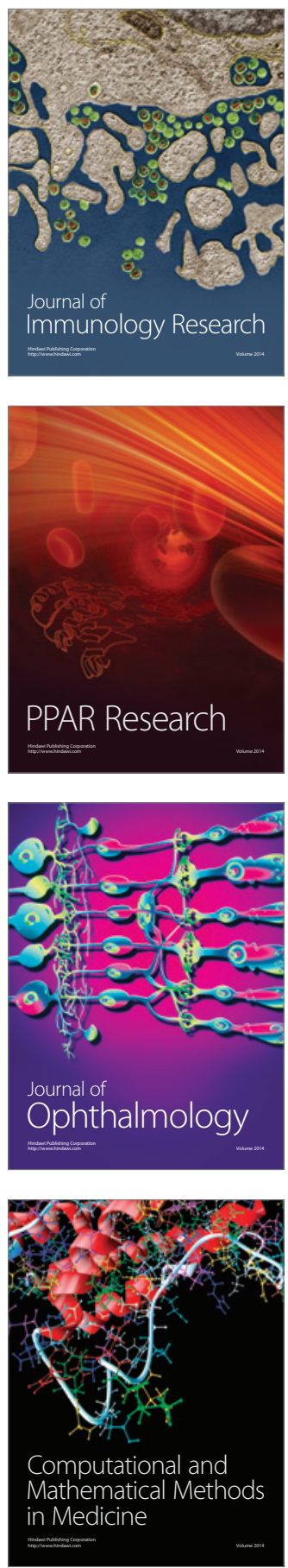

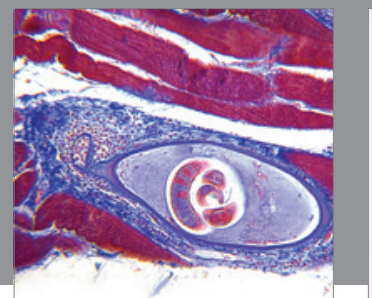

Gastroenterology

Research and Practice
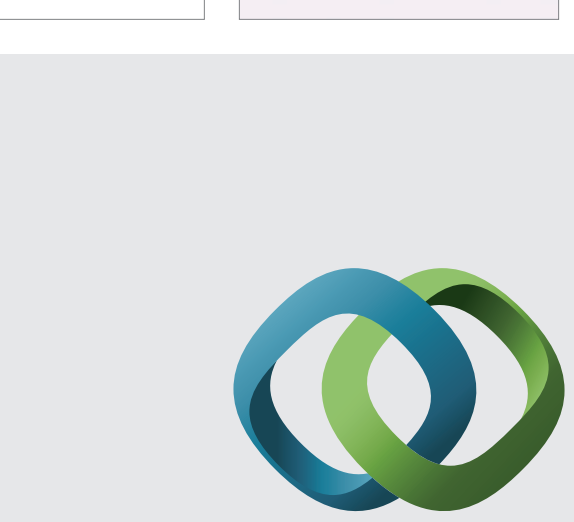

\section{Hindawi}

Submit your manuscripts at

http://www.hindawi.com
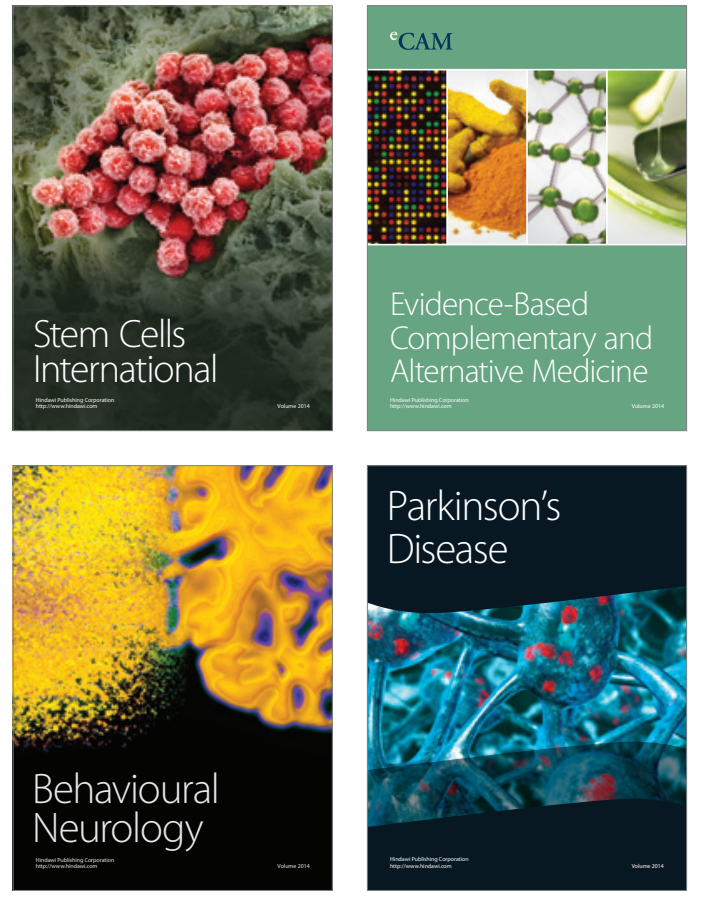
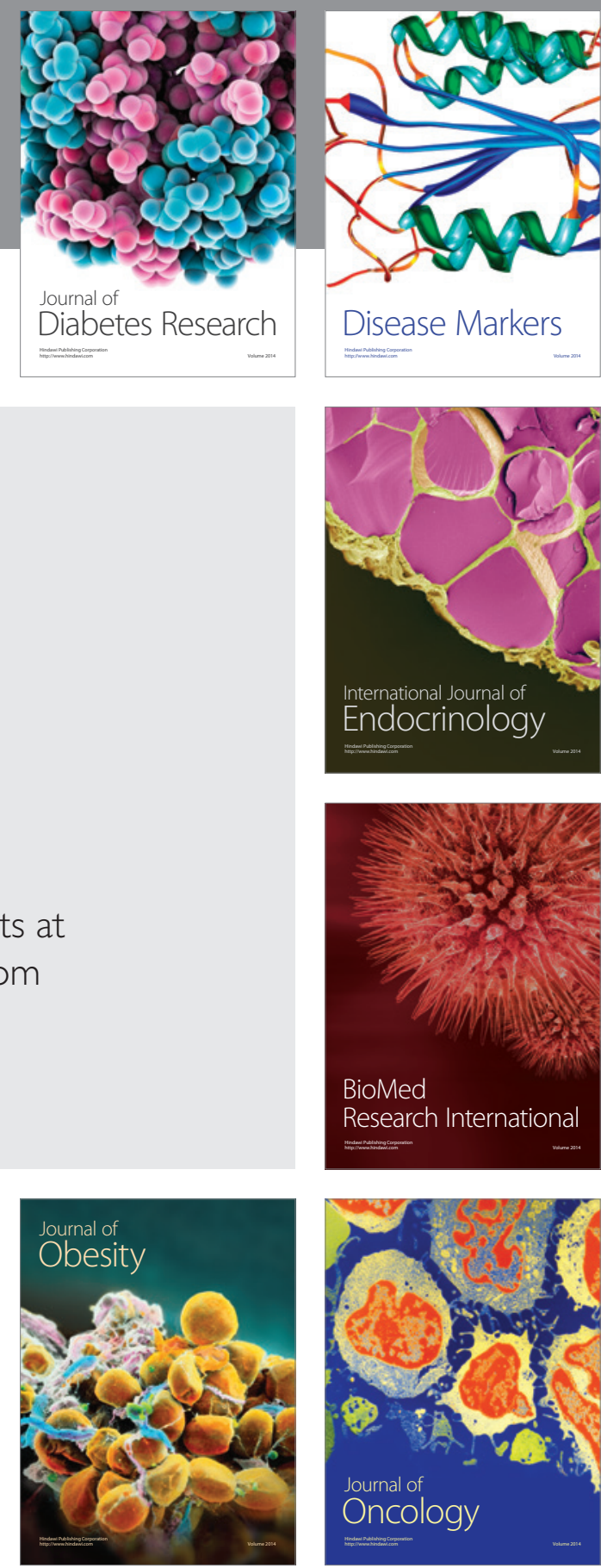

Disease Markers
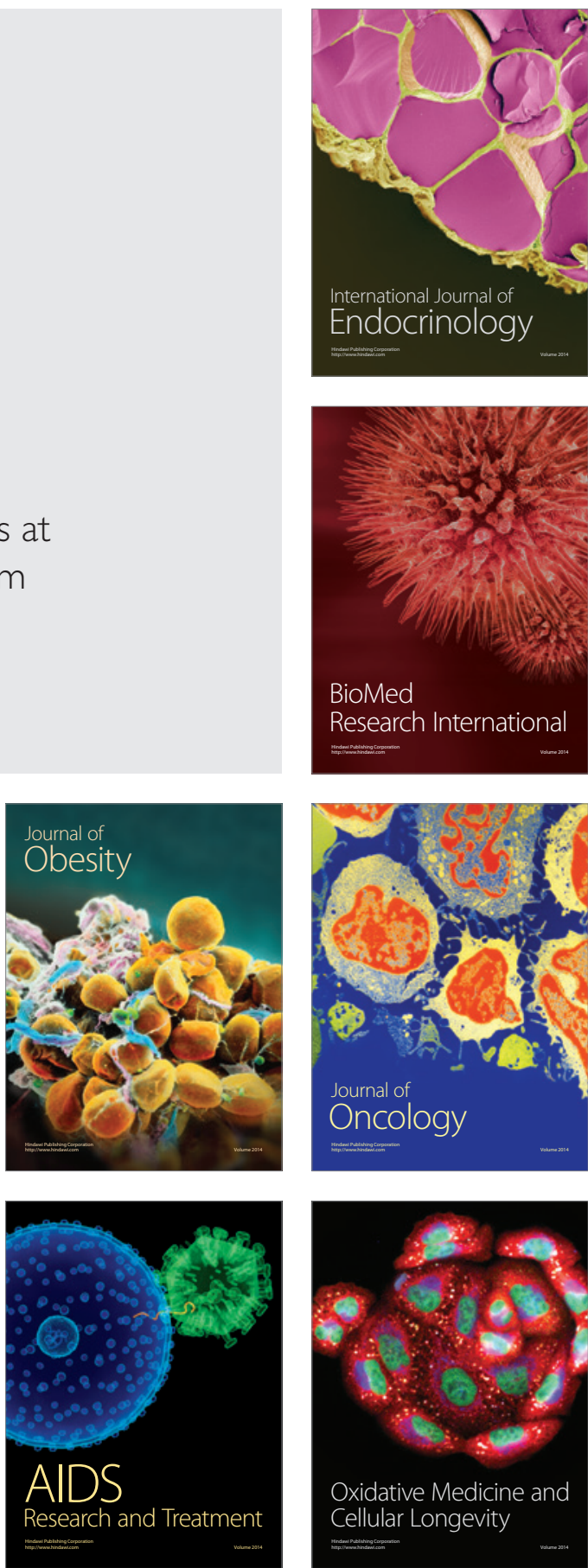